\title{
Issues on Vector Related Diseases Transmission: People's Perception \& Practices
}

\author{
*MM Rahman ${ }^{1}$, A Rahman², R Jnui ${ }^{3}$, A Kawser ${ }^{4}$, KO Shahin ${ }^{5}$
}

\begin{abstract}
Background: The vector borne diseases pose an immense public health concern and also a growing urban and rural problem. The aim of this study was to findout the perception and practices among the rural households regarding vector related diseases in some selected villages of Dhamrai Upazila.

Material and Methods: This descriptive cross sectional study was carried out among 1380 respondents by purposive sampling technique during the period from $6^{\text {th }}$ to $8^{\text {th }}$ January, 2018 in different villages of Dhamrai Upazila, Dhaka..

Results: Then study revealed that majority of the respondents $89 \%$ were Muslims by religion and about $65 \%$ respondents were found within the age 25-55 years. (mean age 37.81 14.72 years). Out of 1380 respondents, majority $87 \% \& 86 \%$ mentioned Mosquitos and Houseflies as vectors transmitting the diseases followed by $48 \%$ Itch mite, $45 \%$ Louse and $27 \%$ Sandflies. About $85 \%$ \& $88 \%$ mentioned Malaria \& Dengue fever transmitted by vectors followed by $58 \%$ Chikungunya, $42 \%$ Kala azar, $13 \%$ Filariasis and 44\% Typhoid fever. However, 71\%, 83\%, 59\% \& 3\% respondents mentioned Mosquito bite as the mode of transmission of Malaria, Chikungunya and Filariasis respectively. About 88\%, 75\%, 44\% and 39\% respondents mentioned Personal protection, Avoidance of water collection, Fogging and Insecticidal spraying as the vector control measures. Nevertheless, $92 \%, 81 \%$ and $30 \%$ respondents are found practiced Mosquito net, Mosquito coil and Screening of windows as their usual vector control measures.

Conclusion: In this study community awareness in terms of perceptions, knowledge and practices regarding vector borne diseases are found deficient. There should be intensified efforts in promoting personal protective measures through creating public awareness towards prevention of vector borne diseases in the locality.
\end{abstract}

Key Words: Vector borne diseases, perception \& practices.

\section{Introduction}

tor-borne diseases account for more than $17 \%$ of all infectious diseases, causing more than 1 million deaths every year globally. More than 2.5 billion people in over 100 countries are at risk of contracting Dengue ${ }^{1}$. Many vector-borne diseases namely malaria, dengue, chikungunya, filariasis and kala-azar are prevalent in South-asia and have become serious public health problem ${ }^{2}$.

Vectors are living organisms that can transmit infectious diseases between humans or from animals to humans. Mosquitoes are the best known disease vector. Others include ticks, flies, sandflies, fleas, triatomine bugs and some freshwater aquatic snails. ${ }^{3}$ Vector-borne diseases account for more than $17 \%$ of all infectious diseases, causing more than 1 million deaths annually. ${ }^{3}$ Yet, five vector-borne diseases -

$1 *$ Prof. Dr. Md. Mahfuzar Rahman, Professor and Head Department of Community Medicine, AKMMC

2Dr. Md. Atiqur Rahman, Associate Professor, Department of Community Medicine, AKMMC

${ }^{3}$ Dr. Rizona Jnui, Assistant Professor, Department of Community Medicine, AKMMC

${ }^{4}$ Dr. Abu Kawser, Assistant Professor (CC), Department of Community Medicine, AKMMC

${ }^{5}$ Dr. Khalid Omar Shahin, Lecturer, Department of Community Medicine, AKMMC

*Corresponding Author

Date of submission: 22.07.2018 Date of acceptance: 29.10 .2018

AKMMC J 2019; 10(1) : 32-37 
Chagas disease, dengue/severe dengue, human African trypanosomiasis, leishmaniasis, lymphatic filariasis and schistosomiasis - are among the 17 neglected tropical diseases. ${ }^{4}$ The incidence of dengue has increased 30 -fold over the last 50 years. Up to 50-100 million infections are now estimated to occur annually in over 100 endemic countries, putting almost half of the world's population at risk. ${ }^{5}$ In 2012, there were an estimated 207 million cases and an estimated $6,27,000$ deaths were due to malaria, mostly (90\%) in sub-Saharan Africa. ${ }^{6}$

Many vector-borne diseases are prevalent in the SouthEast Asia Region. These include, among others, mosquitoborne diseases (e.g. malaria, dengue, chikungunya, Japanese encephalitis, lymphatic filariasis), sandfly-borne disease (kalaazar) and snailtransmitted disease (e.g. schistosomiasis). Vector-borne diseases are human illnesses caused by parasites, viruses and bacteria that are transmitted by mosquitoes, sandflies, triatomine bugs, blackflies, ticks, tsetse flies, mites, snails and lice. Every year there are more than $7,00,000$ deaths from diseases such as malaria, dengue, schistosomiasis, human African trypanosomiasis, leishmaniasis, Chagas disease, yellow fever, Japanese encephalitis and onchocerciasis, globally.

Malaria is endemic in all the countries of South-East Asia region except Maldives, which has been malariafree since 1984. WHO estimated that there were 27 million cases and 42000 deaths due to malaria in 2012 in this region, where around 1.4 billion people are at risk. ${ }^{4}$ About 147 million people (mainly the poor and marginalized populations) in three countries (Bangladesh, India and Nepal) are at risk of kala azar. ${ }^{8,9}$ Distribution of vector-borne diseases is determined by complex demographic, environmental and social factors. Global travel and trade, unplanned urbanization and environmental challenges such as climate change can impact on pathogen transmission, making transmission season longer or more intense or causing diseases to emerge in countries where they were previously unknown. ${ }^{10,11}$

The South-East Asia Region has become hyperendemic with regular reporting of dengue cases since 2000. The maximum number of cases $(3,55,525)$ and deaths $(1982)$ were recorded during 2010. ${ }^{12}$ In 2012, a total of 2,57,204 cases and 1229 deaths were reported from this Region. ${ }^{13}$ The purpose of this study was to explore perception an practices of rural households regarding vector borne diseases.

\section{Methodology}

This was a descriptive cross sectional and qualitative study carried out among rural households in different villages (Choibaria, Kumrail, Islampur, Ambagan, Hajipara and Ponchas) of Dhamrai Upazila during the period from $6^{\text {th }}$ to $8^{\text {th }}$ January, 2018. There were 1380 respondents selected purposively. A pre tested structured questionnaire and FGDs were the instruments for data collection. The $3^{\text {rd }}$ year MBBS students (AKMMC-08) were engaged in implementation of questionnaire. Prior interview a consent form duly signed by the respondents was considered as an ethical practice. It was processed and analyzed manually and by using computer.

\section{Results}

Table 1: Distribution of respondents by sociodemographic characteristics $n=1380$

\begin{tabular}{lccc}
\hline Variables & Variables & $\begin{array}{c}\text { Number of } \\
\text { respondents }\end{array}$ & $\begin{array}{c}\text { Percentage } \\
\text { (\%) }\end{array}$ \\
\hline Age & $15-25$ & 290 & 21.0 \\
& $25-35$ & 407 & 29.49 \\
& $35-45$ & 285 & 20.65 \\
& $45-55$ & 205 & 14.84 \\
& $55-65$ & 116 & 8.47 \\
& $65-75$ & 59 & 4.27 \\
Sex & $75-85$ & 18 & 1.28 \\
Educational level & Male & 572 & 41.45 \\
& Female & 808 & 58.55 \\
& Illiterate & 377 & 27.31 \\
& Primary & 413 & 29.93 \\
Occupation & Secondary & 400 & 28.99 \\
& HSC and above & 190 & 13.77 \\
& Service & 124 & 8.99 \\
& Business & 218 & 15.80 \\
& Agriculture & 67 & 4.86 \\
& Housewife & 634 & 45.93 \\
& Day laborers & 130 & 9.42 \\
& Others & 207 & 15.00 \\
Monthly income & $<5,000$ & 302 & 21.88 \\
& $5,001-8,000$ & 255 & 18.48 \\
& $8,0001-11,000$ & 342 & 24.78 \\
& $>11,000$ & 481 & 34.86 \\
\hline \multirow{5}{*}{} & & & \\
\hline & &
\end{tabular}


About $65 \%$ respondents were found within age of 25-55 years with mean age 37.89 and \pm SD 14.72. Majority (59\%) were female. About $30 \%$ and $29 \%$ respondents were found primary and secondary level of education. However, $22 \%$ were found monthly income below 5,000 BDT.

Table-II: Distribution of respondents by name of the insect that act a as a vector

\begin{tabular}{lccc}
\hline Name of the insect & Yes & No & Don't Know \\
\hline Mosquito & 1205 & 130 & 45 \\
& $(87.31)$ & $(9.4)$ & $(3.3)$ \\
Houseflies & 1189 & 121 & 70 \\
& $(86.15)$ & $(8.78)$ & $(5.07)$ \\
Itch Mite & 666 & 392 & 322 \\
& $(48.26)$ & $(28.44)$ & $(23.3)$ \\
Louse & 622 & 356 & 402 \\
& $(45.07)$ & $(25.80)$ & $(29.13)$ \\
Sand-fly & 374 & 320 & 686 \\
& $(27.10)$ & $(23.20)$ & $(49.7)$ \\
\hline
\end{tabular}

N.B: Figures in parenthesis indicates percentage

About $87 \%, 86 \%, 48 \%, 45 \%$ and $27 \%$ respondents mentioned Mosquitoes, Houseflies, Itch mite, Louse and sand Fly respectively as a vector.
On the other hand, only $2 \%$ respondents correctly mentioned bite of sandflies as the mode of transmission of kala azar and 93\%, 77\% and 35\% mentioned nothing about the mode of transmission of diseases.

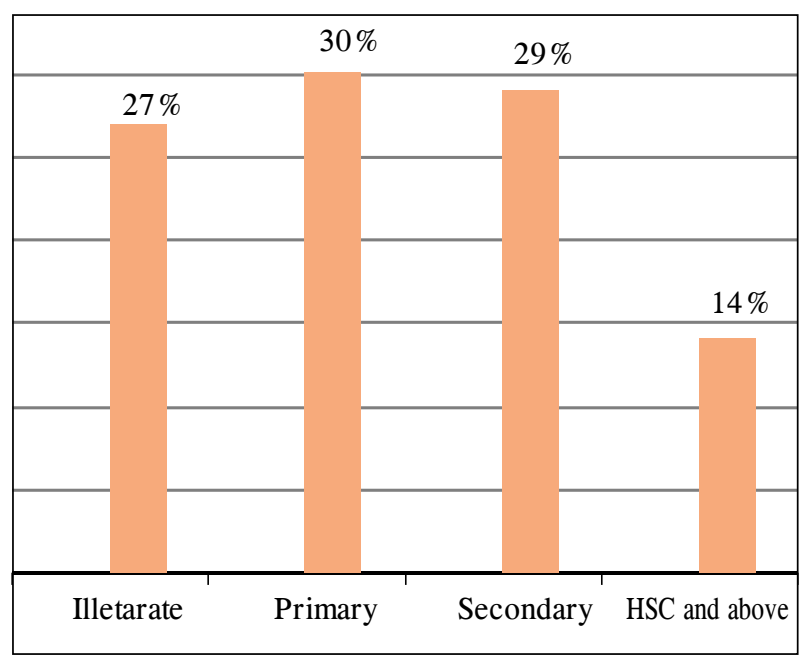

Fig. 1: Bar diagram showing distribution of respondents by level of education.

It shows that about $27 \%$ respondents were found illiterate and $3 \%$ and $29 \%$ respondents were found primary and secondary level of education respectively.

Table-III: Distribution of respondents by knowledge on mode of transmission of common vector borne diseases $\mathrm{n}=$ Multiple response

\begin{tabular}{|c|c|c|c|c|c|c|}
\hline \multirow[t]{2}{*}{ Name of Diseases } & \multicolumn{5}{|c|}{ Mode of Transmission } & \multirow[t]{2}{*}{ Total } \\
\hline & Bite of Mosquito & Bite of Sandflies & $\begin{array}{c}\text { Food contamination } \\
\text { by Houseflies }\end{array}$ & Impure water Intake & Don't Know & \\
\hline \multirow[t]{2}{*}{ Malaria } & 1108 & 23 & 110 & 106 & 212 & 1559 \\
\hline & $(71.08)$ & $(1.47)$ & $(7.05)$ & $(6.8)$ & $(13.6)$ & $(100)$ \\
\hline \multirow[t]{2}{*}{ Dengue } & 1202 & 11 & 39 & 62 & 127 & 1441 \\
\hline & (83.4) & $(0.7)$ & $(2.7)$ & (4.39) & $(8.81)$ & (100) \\
\hline \multirow[t]{2}{*}{ Chikungunya } & 829 & 20 & 32 & 31 & 492 & 1404 \\
\hline & $(59.04)$ & $(1.52)$ & $(2.2)$ & $(2.2)$ & $(35.04)$ & $(100)$ \\
\hline \multirow[t]{2}{*}{ Kala-azar } & 223 & 34 & 28 & 37 & 1063 & 1385 \\
\hline & $(16.23)$ & $(2.450)$ & $(2.02)$ & $(2.6)$ & $(76.7)$ & $(100)$ \\
\hline \multirow[t]{2}{*}{ Filariasis } & 51 & 5 & 14 & 32 & 1289 & 1391 \\
\hline & $(3.6)$ & $(.50)$ & (1) & $(2.3)$ & $(92.60)$ & $(100)$ \\
\hline
\end{tabular}

About $71 \%, 83 \%, 59 \%$ respondents correctly mentioned mosquito bite as a mode of transmission of Malaria, dengue, chikungunya and Filariasis respectively. 
Table -IV: Distribution of respondents by practice of vector control measures $n=1380$

\begin{tabular}{lccc}
\hline $\begin{array}{l}\text { Practice of vector } \\
\text { control measures }\end{array}$ & Yes & No & Total \\
\hline Use of repellent & 212 & 116 & 1380 \\
vaporizer & $(15.36)$ & $(8.41)$ & $(100)$ \\
Use of Mosquito net & 1264 & 116 & 1380 \\
& $(91.59)$ & $(8.41)$ & $(100)$ \\
Screening of windows & 414 & 966 & 1380 \\
& $(30)$ & $(70)$ & $(100)$ \\
Use of repellent cream & 55 & 1325 & 1380 \\
& $(4)$ & $(96)$ & $(100)$ \\
Use of Mosquito coils & 1126 & 254 & 1380 \\
and net & $(81.5)$ & $(18.5)$ & $(100)$ \\
\hline
\end{tabular}

About 92\%, 81\% and 30\% respondents practiced Mosquito net, coils, screening of windows as the vector control measures. However, 96\%, $85 \%$ and $75 \%$ didn't practice these accordingly.

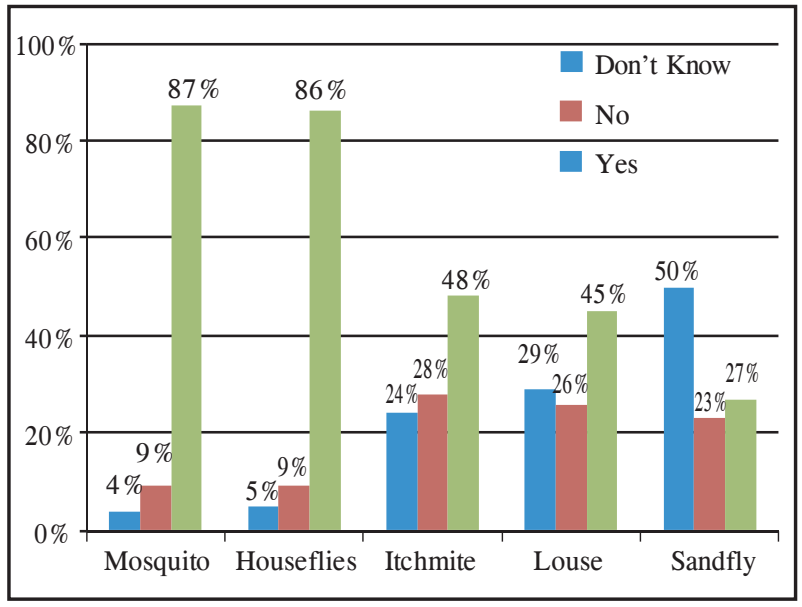

Fig. 2: Multiple bar diagram showing distribution of respondents by knowledge on name of insect that act as a vector

It shows that about $87 \%$ and $86 \%$ respondents mentioned Mosquitos and Houseflies as vector followed by $48 \%$ Itch mite, $45 \%$ louse and $27 \%$ Sandflies.

\section{Focus Group Discussions (FGDs)}

There was spontaneous exchange of ideas among the participants However, participants offered opinion related to itch mite and only few of them knew that itch mite can cause disease. In terms of control measures each and every one had clear conception that mosquito bite is the mode of transmission of disease but the other misconception they had were contaminated foods, ripen foods and poor sanitation etc. Regarding the practice of vector control measures participants response was very poor.

\section{Discussion}

A descriptive cross sectional study was carried out among 1380 rural households of Dhamrai Upazila. The aim of this study was to find out the perception and practices among the rural households regarding vector related diseases in Dhamrai Upazila.

The study reveals that majorities (89\%) of the respondents were Muslims and 65\% respondents were found within age of 25-55 years with mean age 37.81 yrs and $\mathrm{SD} \pm 14.72$. About $41 \%$ were male and $59 \%$ were female respectively. The literacy rate of the respondents was about $73 \%$ of whom $29 \%$ had secondary level of education. Among the respondents $87 \%, 86 \%, 48 \%, 45 \%$ \& $27 \%$ mentioned Mosquitos, Houseflies, Itch mites, Louse and Sandflies respectively as the vector. Similarly about $85 \%, 88 \%, 58 \%, 42 \% 13 \%$ and $44 \%$ respondents mentioned Malaria, Dengue, Chikungunya, Kala azar, Filariasis and Typhoid fever as the vector borne disease. However, $67 \%$, $37 \%, 28 \%, 25 \%$ \& $11 \%$ respondents mentioned nothing about the above stated diseases regarding transmission. In this study participants had good knowledge regarding vector and vector transmitted diseases which is similar to the study done in India 9 .

Regarding mode of transmission of common vector borne diseases, about $71 \%, 83 \%, 59 \%$ \&3\% respondents correctly mentioned Mosquito bite as the mode of transmission of Malaria, Dengue, Chikungunya and Filariasis respectively. On the other hand, only $2 \%$ respondents correctly mentioned bite of Sandflies as the mode of transmission of Kala azar and 93\%, 77\% \& 35\% respondents mentioned nothing about the mode of transmission of Filariasis, Kala azar and Chikungunya respectively. This is in contrast to the result of study by Taran et al. ${ }^{7}$. Information on knowledge on vector control measures, about $88 \%$, $75 \%, 44 \%$ \& 39\% respondents mentioned personal protection, avoidance of water collection, fogging and insecticidal spraying respectively as the vector 
control measures and 52\%, $18 \%$ \& $15 \%$ respondents were unaware about the vector control measures.

Regarding practices of vector control measures about $92 \%, 81 \%$ \& $30 \%$ respondents practiced mosquito nets, mosquito coils, screening of windows respectively as the vector control measures.

\section{Conclusion}

Various studies had been undertaken among the rural people in the world and in Bangladesh, but the information on knowledge and a practice regarding the vector borne diseases at the community level is still inadequate. In this study, it was found that a moderate proportion of people did not have sufficient knowledge regarding the name of vector and the diseases transmitted by them. A certain proportion of people did not have adequate knowledge regarding mode of transmission of Chikungunya, Kala azar and Filariasis. Regarding methods and practice of vector control measures, deficiency in knowledge also found in certain proportion of people. However, it was found a good proportion of people having adequate knowledge regarding the name of vector \& diseases transmitted by them, their mode of transmission as well as different control measures for the prevention of vector borne diseases. This study also examined the perception \& practices among the rural households regarding vector related diseases at Dhamrai Upazila in particular.

\section{Recommendations}

Considering the findings of present study recommendations are as follows

- Community based health education program is needed to increase the knowledge of the people regarding name of specific insect and the diseases transmitted by them.

- Development strategy to utilize mass communication method to educate people about the mode of transmission of different vector borne diseases.

- Intensified efforts should be made towards creating public awareness and strengthening knowledge and practice of vector control measures to prevent vector borne diseases.
Further large scale in depth study is needed to formulate policy in regards to prevent common vector borne diseases.

\section{Acknowledgement}

It is our pleasure to acknowledge Principal and Vice -principal of Anwer Khan Modern Medical College to support in conducting this study. We also gratefully acknowledge Director of NIPSOM and his support stuffs at Dhamrai THC in providing accommodation and guidance during out stay at their premises. We are thankful to the support staffs of Dhamrai THC as well. Thanks to our AKMMC-08 batch students for their hard work from the very beginning in conducting and implementing this study protocol and their active participation for data collection in particular. Last but not least the people of the study area are gratefully acknowledged as key informants.

Conflict of interest: This paper has no conflict of interest among the authors.

\section{References}

1. Fact sheet on Vector Borne Diseases, World Health

2. Organization http: //www. who.int/ Mediacentre/ fact sheets /fs387/en/2. Annual Report 2014-1, national vector Borne Disease Control Programme, Director General of Health Services, Government of India

3. World Health Organization, orld Health Day-7 April 2014. Geneva: WHO, 2014.http:// www.who.int/ campaigns/ world-healthday/2014/evevt/en/-accessed 28 March 2014

4. World Health Organization. World Health Day: protect yourself from vector borne diseases. Geneva: HO, 2014. http:// ww.who.int/ campaingns/ world health day/2014/en/-accessed 28 March 2014

5. World health Organization, Neglected tropical diseases. Geneva: http:// www.who.int/ neglected -diseases/ diseases/en/-accessed 28 march 214

6. World Health Organization. Dengue Control. Geneva: http://www.who.intdengue control/en/accessed 28 march 2014. 
7. World Health Organization. World Malaria report2013. Geneva: HO, 2013. http:// www.who.int/ Malaria/pblications/World Malaria-report-2013/en/accessed28 march 2014

8. World Health Organization, Regional Office for South East Asia. The regional strategic plan for elimination of lymhatic filariasis, 2010-2011. New Delhi: WHO - SEARO, 2012.http://www. Earo.ho.int/entity/world-health -day/214/LFCD203.pdf-accessed 28 March 2014

9. World Health Organization, Regional office for South East -Asia. Regional strategic framework for elimination of Kala-azar from the South East Asia Region, 2011-2015, New Delhi: WHOSEARO, 2012

10. Dash AP,Bhatia R, Karla NLL. Dengue in South East Asia: an appraisal of case management and vector control. Dengue Bulletin. 2012; 36: 1-13

11. World Health Organization, Regional Office for South East Asia. Aide memorie dengue. New Delhi:HO-SEARO.http://ww.earo. who.int/entity/world-health-day/2014/Addememorie-Dengue.pdf-accessed 28 March 2014
12. World Health Organization. Chikungunya. Fact sheet. http://www. Searo.who.int/entity/worldhealth- Day/2014/ Chikungunya-factsheet-A4 pdf-accessed 28 March 2014.

13. http// www. thedailystar.net/ country/ Bangladeshi-women susceptible -mosquitoborne diseases-131145

14. World Health Organization. Chikungunya. Fact sheet. http://www. Searo.who.int/entity/worldhealth- Day/2014/ Chikungunya-factsheet-A4 pdf-accessed 28 March 2014.

15. Pallavi, V tenglikar, $\mathrm{M}$ Hussain, et al. Knowledge and practice regarding mosquito borne disease among people of an urban area in Klaburgi, Karnatak. National Journal of Community Medicine; 2016; 3(7): 223-225. 